Published in final edited form as:

Lancet Gastroenterol Hepatol. 2017 April ; 2(4): 269-276. doi:10.1016/S2468-1253(17)30004-3.

\title{
Risk of colorectal cancer in Asian patients with ulcerative colitis: a systematic review and meta-analysis
}

\author{
Sawan Bopanna, M.D ${ }^{1}$, Ashwin N Ananthakrishnan, M.D², Saurabh Kedia, M.D ${ }^{1}$, Vijay \\ Yajnik, M.D, Ph.D. ${ }^{2}$, and Prof. Vineet Ahuja, M.D1 \\ ${ }^{1}$ Department of Gastroenterology, All India Institute of Medical Sciences, New Delhi, India \\ 2Massachusetts General Hospital, Crohn's and Colitis Center, 165 Cambridge St., Boston, MA, \\ U.S.A
}

\section{Summary}

\begin{abstract}
Background-The increased risk of colorectal cancer in ulcerative colitis is well known. The risk of sporadic colorectal cancer in Asian populations is considered low and risk estimates of colorectal cancer related to ulcerative colitis from Asia vary. This meta-analysis is an Asian perspective on the risk of colorectal cancer related to ulcerative colitis.
\end{abstract}

Methods-We searched PubMed and Embase for terms related to colorectal cancer in ulcerative colitis from inception to July 1, 2016. The search for published articles was done by country for all countries in Asia. We included studies with information on the prevalence and cumulative risk of colorectal cancer at various timepoints. A random-effects meta-analysis was done to calculate the pooled prevalence as well as a cumulative risk at 10 years, 20 years, and 30 years of disease.

Findings-Our search identified 2575 articles; of which 44 were eligible for inclusion. Our analysis included a total of 31287 patients with ulcerative colitis with a total of 293 reported colorectal cancers. Using pooled prevalence estimates from various studies, the overall prevalence was $0.85 \%$ (95\% CI 0.65-1.04). The risks for colorectal cancer were $0.02 \%$ (95\% CI 0.00-0.04) at 10 years, $4.81 \%(3 \cdot 26-6 \cdot 36)$ at 20 years, and $13.91 \%(7 \cdot 09-20 \cdot 72)$ at 30 years. Subgroup analysis by stratifying the studies according to region or period of the study did not reveal any significant differences.

Interpretation-We found the risk of colorectal cancer in Asian patients with ulcerative colitis was similar to recent estimates in Europe and North America. Adherence to screening is therefore necessary. Larger population-based, prospective studies are required for better estimates of the risk.

Corresponding Author Information: Dr. Vineet Ahuja, Professor, Room No 3093, Department of Gastroenterology, Third Floor, Teaching Block, All India Institute of Medical Sciences, New Delhi, India, 110029, vineet.aiims@ gmail.com, Phone No.: 91-11-26593300, Fax: 91-11-2658663.

Contributors

SB and SK were responsible for data acquisition, analysis, and interpretation, and drafting of the manuscript. ANA was responsible for data acquisition, analysis, and interpretation, drafting of the manuscript, and statistical analysis. VY was responsible for analysis and interpretation, and drafting of the manuscript. VA was responsible for the study concept and design, analysis and interpretation, and drafting of the manuscript. Declaration of interests We declare no competing interests. 


\section{Introduction}

The incidence of ulcerative colitis is increasing in Asia. ${ }^{1,2}$ With this rising burden and the advent of effective treatments, clinicians are increasingly likely to encounter complications of long-standing ulcerative colitis. Colorectal cancer is an important complication in longstanding ulcerative colitis and contributes substantially to the morbidity and mortality associated with this disease. The prevalence of colorectal cancer among those with ulcerative colitis was initially estimated to be $3.7 \%$ by Eaden and colleagues ${ }^{3}$ with a cumulative risk of $18 \%$ at 30 years. Recent studies have reported a secular decline in the incidence of colorectal cancer, but compared with the general population the risk remains elevated in those with long-standing extensive colitis. Most estimates of cancer risk in ulcerative colitis have been from populations in Europe and North America, with few studies in Asia. However, there are several reasons to postulate that the risk might be different in Asia. First, the genetic basis of ulcerative colitis is different in those of Asian ethnicity 4,5 compared with the white population, and this might affect the risk of disease progression, including that of colorectal cancer. Second, sporadic colorectal cancer is infrequent in Asian countries such as India and China compared with Europe and North America. ${ }^{6}$ Third, effective treatments that achieve mucosal healing, and consequently might reduce the rate of colorectal cancer through superior control of inflammation, are less widely available in Asia. ${ }^{7,8}$ Finally, surveillance colonoscopy and adequate histological sampling are less frequently practiced in Asia. Existing studies from Asian populations have been based on small cohorts, have imprecise estimates of risk, and have yielded inconsistent results. However, an accurate estimate of risk is essential to formulate region specific guidelines for screening for dysplasia and colorectal cancer in ulcerative colitis. Consequently, we did this systematic review and meta-analysis to assess the risk of colorectal cancer in patients with ulcerative colitis in referral and population based cohorts in Asia and to determine whether regional variation exists in such risk.

\section{Methods}

Search strategy and selection criteria A search for relevant articles was done on PubMed and Embase (from inception to July 1, 2016) for all full-text articles pertaining to the incidence or prevalence of colorectal cancer in patients with ulcerative colitis. No language restrictions were used. Information from articles not in the English language was translated using Google's translation tools to acquire relevant information where available. Studies were identified using the terms "colorectal cancer" OR "colon cancer" OR "rectal cancer" AND "ulcerative colitis". These search terms were combined with "Asia" and each individual country serially (eg, "India", "China", "Japan", "Korea") to identify studies that provided this risk from an Asian cohort. Asian countries included Afghanistan, Armenia, Azerbaijan, Bahrain, Bangladesh, Bhutan, Brunei, Cambodia, China, Cyprus, Georgia, India, Indonesia, Iran, Iraq, Israel, Kazakhstan, Kuwait, Kyrgyzstan, Laos, Lebanon, Malaysia, Maldives, Mongolia, Myanmar, Nepal, North Korea, Oman, Pakistan, Palestine, Philippines, Qatar, Russia, Saudi Arabia, Singapore, South Korea, Sri Lanka, Syria, Taiwan, Tajikistan, Thailand, Timor Leste, Turkey, Turkmenistan, United Arab Emirates, Uzbekistan, Vietnam, and Yemen. An example search strategy can be found in the appendix. Additionally, the list of citations from each article, review articles on the topic, and other systematic reviews were 
manually searched to identify other potentially relevant studies. The abstracts presented at Digestive Disease Week and Asia Pacific Digestive Week for the years 2013, 2014, and 2015 were reviewed for relevant information. We included all full-text studies and abstracts with information on ulcerative colitis and the occurrence of colorectal cancer. These studies included hospital, population-based, and registry-based cohorts. Surgical series that included patients with ulcerative colitisrelated colorectal cancer were excluded. Case series describing the occurrence of colorectal cancer in ulcerative colitis without being able to provide an estimate of risk or prevalence were not included nor were those that combined ulcerative colitis-related colorectal cancer and sporadic cancer. The decision for inclusion of each study was made independently by two authors (SB and ANA). Disagreements about inclusion of studies or extraction of data were resolved by consensus between the authors (SB and ANA)

\section{Data extraction}

Relevant data extracted included the year of publication, study period, source country, study design, the total number of patients with ulcerative colitis and those with colorectal cancer, and duration of follow-up of the cohort. We extracted data for the prevalence of colorectal cancer among patients with ulcerative colitis and, when available, cumulative risk of colorectal cancer at 10 years, 20 years, and 30 years after diagnosis of ulcerative colitis. Predictive factors for the development of colorectal cancer were also extracted when available, including the age of onset, duration and extent of disease, smoking status, the presence of concomitant primary sclerosing cholangitis, and family history of colorectal cancer. The MOOSE guidelines ${ }^{9}$ were followed for data collection and presentation. We assessed the methodological quality of each study including the use of the NewcastleOttawa quality assessment scale (NOS) for cohort studies..$^{10}$ The NOS assigns 4 points for selection, 2 points for comparability, and 3 points for exposure-outcome (appendix); a score of 9 points reflects the highest quality.

\section{Statistical analysis}

The primary outcome of the study was the prevalence of colorectal cancer. Prevalence was estimated from the total population at risk and number of colorectal cancer cases assuming a Poisson distribution for calculation of $95 \%$ CIs. Pooled prevalence was assessed using the DerSimonian and Laird random effects model when significant study heterogeneity was present $\left(\mathrm{I}^{2}>50 \%\right.$ or $\left.\mathrm{p}<0.005\right)$ or a fixed effects model in the absence of significant heterogeneity. Similarly, 95\% CIs for the cumulative risks at 10 years, 20 years, and 30 years were calculated using the risk estimates provided, applying a Poisson distribution.

Prevalence estimates and $95 \%$ CIs from studies with zero events were treated by adding 0.5 cases to both the numerator (number of colorectal cancer events) and denominator (total number of ulcerative colitis events) consistent with recommended practice. ${ }^{11}$ We estimated the influence of a study by sequentially excluding each one. Publication bias was assessed through graphical visualisation of the funnel plot, Begg's test, and Egger's test. Metaregression was done to identify influential variables with a p value less than 0.05 indicating a significant effect. Sensitivity analyses were done as post-hoc analyses according to the type of study and study period. A priori subgroup analyses were done by stratifying by region 
(south Asia, east Asia, and the Middle East). Between subgroup p values were calculated from meta-regression. All statistical analyses were done using Stata 14.2.

\section{Role of the funding source}

The funder of the study had no role in study design, data collection, data analysis, data interpretation, or writing of the report. SB and the corresponding author had full access to all the data in the study; the corresponding author had final responsibility for the decision to submit for publication.

\section{Results}

Our search identified 2575 studies. After reviewing the titles and abstracts, 64 studies were included for review of the full text (figure 1). After excluding 20 studies that did not provide enough data to estimate risk of colorectal cancer, examined colorectal cancer risk in those with a J pouch, did not separate out ulcerative colitis from Crohn's disease, and those that included only those with proctitis, surgical series that only included patients with ulcerative colitis-related colorectal cancer or analysed only colorectal cancer-related mortality, 44 studies were included in the final meta-analysis. Studies were of good quality as assessed by the NOS quality assessment scale for cohort studies. ${ }^{10}$ All studies had a score of greater than 4. Most of the included studies were retrospective (36 articles). Among the included studies, six were from India, ${ }^{12-17}$ four from Korea, ${ }^{18-21}$ seven from Japan, ${ }^{22-28}$ eight from China, ${ }^{29-36}$ three each from Taiwan, ${ }^{37-39}$ Singapore, ${ }^{40-42}$ Malaysia, ${ }^{43-45}$ and Israel, ${ }^{46-48}$ two from Turkey, ${ }^{49,50}$ and one each from Kuwait, ${ }^{51}$ Sri Lanka, ${ }^{52}$ Jordan, ${ }^{53}$ Iran, ${ }^{54}$ and Oman. ${ }^{55}$ Six studies reported colorectal cancer risk in patients undergoing routine surveillance. ${ }^{13,17,24,27,28,49}$ The prevalence of colorectal cancer in ulcerative colitis was available from all studies. Of 11 studies that reported the cumulative risk of colorectal cancer at 10 years, 20 years, and 30 years, one study ${ }^{41}$ was excluded from the analysis because it combined colorectal cancer and dysplasia (table). The period of study ranged from 1974 to 2015. The mean duration of ulcerative colitis was 8.0 years (SD 3.04). Five studies $^{21,43,44,51,55}$ reported no colorectal cancer (table).

The pooled analysis for the prevalence of ulcerative colitis-associated colorectal cancer included 31287 patients with ulcerative colitis with 293 reported colorectal cancers. The pooled prevalence of colorectal cancer in our cohort was $0.85 \%$ (95\% CI 0.65-1.04) with significant heterogeneity between the studies $\left(\mathrm{I}^{2}=54.2 \%\right.$, $\mathrm{p}<0 \cdot 0001$; figure 2$)$. We repeated the analysis stratifying by type of study and region within Asia. Registry-based studies yielded similar pooled prevalence estimates $(0.77 \%, 95 \%$ CI $0.28-1 \cdot 25)$ to hospital-based studies $(0.66 \%, 0.49-0.82, \mathrm{p}=0.87$; data not shown). We found no regional variation within Asia with statistically similar prevalence estimates from east Asia (21 studies; 0.71\%, 95\% CI 0.50-0.92), south Asia (14 studies; 1.33\%, 0.84-1.82), and the Middle East (nine studies; $0 \cdot 85 \%, 0 \cdot 31-1 \cdot 39)$, though numerically the prevalence was higher in south Asia ( $\mathrm{p}=0 \cdot 067$; appendix $\mathrm{p} 4$ ). We repeated the analysis by decade of study and did not identify any secular trends in the prevalence of colorectal cancer from those studies including patients diagnosed before 1980 (0.98\%, 95\% CI 0.54-1.43), 1980-89 (0.76\%, 0.04-1.49),1990-99 (1.05\%, $0 \cdot 55-1 \cdot 54)$, and after $2000(0 \cdot 74 \%, 0 \cdot 45-1 \cdot 03 ; \mathrm{p}=0 \cdot 62$; data not shown). 
A random effects pooled model yielded cumulative risks of colorectal cancer in patients with ulcerative colitis of $0.02 \%(95 \% \mathrm{CI} 0.00-0.04)$ at 10 years, $4.81 \%(3 \cdot 26-6 \cdot 36)$ at 20 years, and $13.91 \%(7.09-20 \cdot 72)$ at 30 years after diagnosis (figure 3$)$.

Results of the meta-regression examining the effect of various parameters on study outcomes are shown in the appendix. Among the other parameters included in the meta-regression, neither size of the cohort, study region, nor decade of study affected the risk. There was no significant change in the pooled prevalence estimates after sequential exclusion of any study. Graphical visualisation of the funnel plot (appendix p 5), Begg's test ( $\mathrm{p}=0.04)$, and Egger's test $(\mathrm{p}<0.0001)$ revealed possible publication bias (data not shown).

\section{Discussion}

In this systematic review and meta-analysis, we show a prevalence of colorectal cancer of $0.85 \%$ in Asia, with no further geographical variation within this region. Colorectal cancer is one of the most important complications of long-standing ulcerative colitis. Several studies, primarily from Europe and North America, initially estimated the risk to be as high as $18 \%$ after 30 years of ulcerative colitis. Although recent studies have estimated this risk to be lower at present, the risk is, nevertheless, higher than in the general population. As there exist ethnic differences in susceptibility to ulcerative colitis as well as colorectal cancer, ${ }^{56}$ it is important for accurate estimates of colorectal cancer risk in populations where inflammatory bowel disease is emerging to accurately inform patient care and surveillance practices. The overall prevalence of $0.85 \%$ is much lower than the prevalence of $3.7 \%$ reported by Eaden and colleagues ${ }^{3}$ in their meta-analysis of 116 studies. The cumulative risk at 30 years in our analysis was $13.91 \%$, compared with $18 \%$ in the Eaden study. However, more recent studies that have examined secular decline in rates of colorectal cancer in ulcerative colitis have arrived at a prevalence in western populations similar to our results. For example, Jess and colleagues57 reported an estimate of $1.6 \%$ over a period of 14 years in their meta-analyses of population based studies, slightly higher than our estimate. In an analysis of cumulative incidence, Lutgens and colleagues 58 estimated a risk of $1 \%$ after 10 years, $2 \%$ after 20 years, and $5 \%$ after more than 20 years of disease duration, similar to our estimates.

We did not find any secular decline in the incidence of colorectal cancer among the studies included in our meta-analysis. This finding is in contrast with some other recent metaanalyses, which have suggested a decrease over the past few decades. Meta-analyses by Castaño-Milla and colleagues59 and several other studies60-62 reported a decline in ulcerative colitis associated with colorectal cancer over the past six decades. There could be several reasons for this difference in results. First, the number of patients in the studies included in our meta-analyses was small, limiting our power to detect a decrease in the incidence of a relatively rare outcome. Second, the mean duration of follow-up was short, and declines in risk might be more apparent in those with longer-standing ulcerative colitis with a greater absolute risk. Third, one hypothesis for the decline in colorectal cancer risk in Europe and North America has been widespread use of effective therapies such as biological agents early on in the disease course, leading to resolution of mucosal inflammation, and thus risk. Because such treatments are still infrequently used in Asia, ${ }^{7,8}$ a similar decline 
might not yet be apparent. Fourth, systematic surveillance programmes in Europe and North America might have also contributed to a reduction in colorectal cancer risk because such surveillance procedures have been shown to reduce the risk of colorectal cancer. ${ }^{45}$ The less frequent adoption of such surveillance programmes might be the reason for absence of a declining incidence of colorectal cancer over time. There are several implications from our study. First, although the risk of sporadic colorectal cancer is much lower in Asian countries than in Europe and North America, ${ }^{6}$ we found the prevalence estimates of colorectal cancer in patients with ulcerative colitis to be comparable or only slightly reduced compared with recent estimates from other meta-analyses. Consequently, regional recommendations need to emphasise the importance of surveillance programmes in patients with long-standing ulcerative colitis in Asia. As use, acceptance, and cost of colonoscopies might prove to be important barriers, there is a need for further examination of non-invasive screening tools for colorectal cancer in patients from resource-poor settings. Also, there might be a need to treat to mucosal healing to reduce the risk of colorectal cancer in those with long-standing ulcerative colitis. We readily acknowledge several limitations of our study. First, although 44 eligible studies provided prevalence of colorectal cancer cross-sectionally, few studies were longitudinal and allowed for estimation of risk at 10 years, 20 years, and 30 years. Most studies (36 studies) were retrospective. Second, a large number of included studies were hospital-based, which tend to yield higher prevalences than do population-based studies. Fourth, the mean duration of ulcerative colitis was low and the number of patients in each study was small, precluding robust calculations of risk at 20 years and 30 years after diagnosis.

Finally, too few studies provided data on low-grade or high-grade dysplasia within our cohort, or on other risk factors for colorectal cancer. Although we did not include "dysplasia" in our search terms, we ran a test search in PubMed combining "ulcerative colitis" AND "dysplasia" in each Asian country and did not find any additional studies reporting colorectal cancer in ulcerative colitis. We found that there is substantial heterogeneity between the different studies. We attempted to explore the possible causes of this heterogeneity by doing meta-regression and several analyses stratified by study design, location, and other variables. However, similar heterogeneity has been noted in many previous meta-analyses of cancer risk in ulcerative colitis. In the landmark publication by Eaden and colleagues ${ }^{3}$ which serves as a benchmark regarding our estimate of the risk of colon cancer in long-standing ulcerative colitis, a similarly high degree of heterogeneity was noted $(\mathrm{p}<0 \cdot 001)$. As more studies on cancer risk in ulcerative colitis in Asia become available using population-based designs in large cohorts (with more robust estimates and standard errors), this heterogeneity might decrease, yielding more homogeneous risk estimates.

In conclusion, our systematic review and meta-analysis revealed an overall prevalence of colorectal cancer of $0.85 \%$ among patients with ulcerative colitis in Asia, and cumulative risks of $0.02 \%, 4.81 \%$, and $13.91 \%$ at 10 years, 20 years, and 30 years. There is a need for larger population-based longitudinal cohorts to more accurately inform this risk. The comparability of risk estimates with those from North America and Europe suggests that there is a need for similar surveillance strategies regionally. 


\section{Supplementary Material}

Refer to Web version on PubMed Central for supplementary material.

\section{Acknowledgments}

Funding: Indo-US Science and Technology Forum.

\section{References}

1. Ahuja V, Tandon RK. Inflammatory bowel disease: the Indian augury. Indian J Gastroenterol. 2012; 31:294-96. [PubMed: 23150035]

2. Ahuja V, Tandon RK. Inflammatory bowel disease in the Asia-Pacific area: a comparison with developed countries and regional diff erences. J Dig Dis. 2010; 11:134-47. [PubMed: 20579217]

3. Eaden JA, Abrams KR, Mayberry JF. The risk of colorectal cancer in ulcerative colitis: a metaanalysis. Gut. 2001; 48:526-35. [PubMed: 11247898]

4. Yoshitake S, Kimura A, Okada M, Yao T, Sasazuki T. HLA class II alleles in Japanese patients with inflammatory bowel disease. Tissue Antigens. 1999; 53:350-58. [PubMed: 10323339]

5. Cheon JH. Genetics of inflammatory bowel diseases: a comparison between Western and Eastern perspectives. J Gastroenterol Hepatol. 2013; 28:220-26. [PubMed: 23189979]

6. Ferlay, J., Soerjomataram, I., Ervik, M., et al. GLOBOCAN 2012 v1.0. Cancer incidence and mortality worldwide: IARC CancerBase number 11. Lyon, France: International Agency for Research on Cancer; 2013. http://globocan.iarc.fr [accessed Dec 22, 2016]

7. Sung JJ, Kamm MA, Marteau P. Asian perspectives in the management of inflammatory bowel disease: findings from a recent survey. J Gastroenterol Hepatol. 2010; 25:183-93. [PubMed: 19929931]

8. Prideaux L, Kamm MA, De Cruz P, et al. Comparison of clinical characteristics and management of inflammatory bowel disease in Hong Kong versus Melbourne. J Gastroenterol Hepatol. 2012; 27:919-27. [PubMed: 22098103]

9. Stroup DF, Berlin JA, Morton SC, et al. Meta-analysis of observational studies in epidemiology: a proposal for reporting. Meta-analysis Of Observational Studies in Epidemiology (MOOSE) group. JAMA. 2000; 283:2008-12. [PubMed: 10789670]

10. Stang A. Critical evaluation of the Newcastle-Ottawa scale for the assessment of the quality of nonrandomized studies in meta-analyses. Eur J Epidemiol. 2010; 25:603-05. [PubMed: 20652370]

11. Higgins, JPT.Deeks, JJ.Altman, DG., Green, S., editors. Cochrane handbook for systematic reviews of interventions, version 5.1.0 (updated March, 2011). The Cochrane Collaboration; 2011. Special topics in statistics. www.handbook.cochrane.org

12. Desai D, Shah S, Deshmukh A, et al. Colorectal cancers in ulcerative colitis from a low-prevalence area for colon cancer. World J Gastroenterol. 2015; 21:3644-49. [PubMed: 25834332]

13. Shivakumar BM, Lakshmankumar B, Rao L, Bhat G, Suvarna D, Pai CG. Colorectal neoplasia in long-standing ulcerative colitis-a prospective study from a low-prevalence area. Colorect Dis. 2013; 15:e462-68.

14. Venkataraman S, Mohan V, Ramakrishna BS, et al. The risk of colorectal cancer in ulcerative colitis in India. J Gastroenterol Hepatol. 2005; 20:705-09. [PubMed: 15853982]

15. Kochhar R, Goenka MK, Kaushik SP, Gupta NM, Nagi B, Mehta SK. Colorectal carcinoma in Indian patients with idiopathic ulcerative colitis. Eur J Cancer Prev. 1992; 1:293-96. [PubMed: 1467777]

16. Ray G. Incidence and risk factors of colon cancer in a cohort of Indian patients with ulcerative colitis. J Gastroenterol Hepatol. 2010; 25(suppl 2) abstr A79.

17. Bopanna S, Kedia S, Das P, et al. High incidence of ulcerative colitis related colorectal cancer in a low incidence area of sporadic colon cancer. United Eur Gastroenterol J. 2017 (in press). 
18. Choi JK, Kim DW, Shin SY, Park EC, Kang JG. Eff ect of ulcerative colitis on incidence of colorectal cancer: results from the Nationwide Population-Based Cohort Study (2003-2013). J Cancer. 2016; 7:681-86. [PubMed: 27076849]

19. Kim BJ, Yang SK, Kim JS, et al. Trends of ulcerative colitis-associated colorectal cancer in Korea: a KASID study. J Gastroenterol Hepatol. 2009; 24:667-71. [PubMed: 19378391]

20. Lee HS, Park SH, Yang SK, et al. The risk of colorectal cancer in inflammatory bowel disease: a hospital-based cohort study from Korea. Scand J Gastroenterol. 2015; 50:188-96. [PubMed: 25515241]

21. Park SH, Kim YM, Yang SK, et al. Clinical features and natural history of ulcerative colitis in Korea. Inflamm Bowel Dis. 2007; 13:278-83. [PubMed: 17206722]

22. Kamiya T, Ando T, Watanabe O, et al. Suitability of surveillance colonoscopy for patients with ulcerative colitis to detect colorectal cancer: current guidelines miss some early-stage cases. Nagoya J Med Sci. 2015; 77:237-44. [PubMed: 25797989]

23. Fujita T, Ando T, Watanabe $\mathrm{O}$, et al. Clinicopathological study of colorectal cancer occurring in patients with ulcerative colitis: results from a single hospital in Japan. Hepatogastroenterology. 2010; 57:487-92. [PubMed: 20698214]

24. Hata K, Watanabe T, Kazama S, et al. Earlier surveillance colonoscopy programme improves survival in patients with ulcerative colitis associated colorectal cancer: results of a 23-year surveillance programme in the Japanese population. Br J Cancer. 2003; 89:1232-36. [PubMed: 14520452]

25. Ishibashi N, Hirota Y, Ikeda M, Hirohata T. Ulcerative colitis and colorectal cancer: a follow-up study in Fukuoka, Japan. Int J Epidemiol. 1999; 28:609-13. [PubMed: 10480685]

26. Hiwatashi N, Yamazaki H, Kimura M, Morimoto T, Watanabe H, Toyota T. Clinical course and long-term prognosis of Japanese patients with ulcerative colitis. Gastroenterol Jpn. 1991; 26:31218. [PubMed: 1889689]

27. Suzuki K, Muto T, Agawa S, Morioka Y. Dysplasia in ulcerative colitis detected by surveillance colonoscopy. Nihon Shokakibyo Gakkai Zasshi. 1991; 88:1051-59. (in Japanese). [PubMed: 1856998]

28. Nagasako K, Iizuka B, Ishii F, Miyazaki J, Fujimori T. Colonoscopic diagnosis of dysplasia and early cancer in longstanding colitis. J Gastroenterol. 1995; 30(suppl 8):36-39. [PubMed: 8563885]

29. Gong W, Lv N, Wang B, et al. Risk of ulcerative colitis-associated colorectal cancer in China: a multi-center retrospective study. Dig Dis Sci. 2012; 57:503-07. Articles 8 www.thelancet.com/ gastrohep Published online February 20, 2017 http://dx.doi.org/10.1016/S2468-1253(17)30004-3. [PubMed: 21938485]

30. Zhang Q, Sha S, Xu B, Liang S, Wu K. Prevalence of colorectal cancer in patients with ulcerative colitis: a retrospective, monocenter study in China. J Cancer Res Ther. 2015; 11:899-903. [PubMed: 26881538]

31. Zhao YJ, Yuan YZ. Clinical study of the relationship between inflammatory bowel diseases and colorectal neoplasms. J Dig Dis. 2009; 10:113-17. [PubMed: 19426393]

32. Chow DK, Leong RW, Tsoi KK, et al. Long-term follow-up of ulcerative colitis in the Chinese population. Am J Gastroenterol. 2009; 104:647-54. [PubMed: 19262521]

33. Zhang Q. Prevalence of colorectal cancer in patients with ulcerative colitis. J Gastroenterol Hepatol. 2013; 28(suppl 3):807.

34. Zhu X, Dai Y, Chen Z, Lin Y. The clinical and endoscopic characteristics of 476 cases of ulcerative colitis. J Gastroenterol Hepatol. 2013; 28(suppl 3):137.

35. Wang F, Zhang X, Zhou S, et al. Ulcerative colitis-associated adenoma and colorectal cancer: a retrospective case analysis. Chin J Gastroenterol. 2013; 18:233-36.

36. Jiang L, Xia B, Li J, et al. Retrospective survey of 452 patients with inflammatory bowel disease in Wuhan city, central China. Inflamm Bowel Dis. 2006; 12:212-17. [PubMed: 16534423]

37. Kuo CJ, Yu KH, See LC, et al. The trend of inflammatory bowel diseases in Taiwan: a populationbased study. Dig Dis Sci. 2015; 60:2454-62. [PubMed: 25837597]

38. Wei SC, Shieh MJ, Chang MC, Chang YT, Wang CY, Wong JM. Long-term follow-up of ulcerative colitis in Taiwan. J Chin Med Assoc. 2012; 75:151-55. [PubMed: 22541142] 
39. Tung C-C, Wei S-C, Shieh M-J, Chang M-C, Chang Y-T, Wang C-Y. Long-term follow-up of ulcerative colitis in Taiwan. J Gastroenterol Hepatol. 2011; 26(suppl 5):88. [PubMed: 21443718]

40. Ling KL, Ooi CJ, Luman W, Cheong WK, Choen FS, Ng HS. Clinical characteristics of ulcerative colitis in Singapore, a multiracial city-state. J Clin Gastroenterol. 2002; 35:144-48. [PubMed: 12172359]

41. Thia KT-J, Neo S, Soon A, Li H-H, Ling K-L, Kong S-CC. Risk of colorectal cancer and dysplasia in Asian ulcerative colitis patients. J Gastroenterol Hepatol. 2011; 26(suppl 5):121.

42. Lim K, Kwek A, Fock K, et al. Ulcerative colitis in Singapore: epidemiology and clinical features. Inflamm Bowel Dis. 2009; 15(suppl 2):S23.

43. Hilmi I, Singh R, Ganesananthan S, et al. Demography and clinical course of ulcerative colitis in a multiracial Asian population: a nationwide study from Malaysia. J Dig Dis. 2009; 10:15-20. [PubMed: 19236542]

44. Hilmi I, Jaya F, Chua A, Heng WC, Singh H, Goh KL. A first study on the incidence and prevalence of IBD in Malaysia-results from the Kinta Valley IBD Epidemiology Study. J Crohns Colitis. 2015; 9:404-09. [PubMed: 25744112]

45. Tan YM, Goh KL. Ulcerative colitis in a multiracial Asian country: racial diff erences and clinical presentation among Malaysian patients. World J Gastroenterol. 2005; 11:5859-62. [PubMed: 16270398]

46. Gilat T, Lilos P, Zemishlany Z, Ribak J, Benaroya Y. Ulcerative colitis in the Jewish population of Tel-Aviv Yafo. III. Clinical course. Gastroenterology. 1976; 70:14-19. [PubMed: 1245273]

47. Gilat T, Fireman Z, Grossman A, et al. Colorectal cancer in patients with ulcerative colitis. A population study in central Israel. Gastroenterology. 1988; 94:870-77. [PubMed: 3345886]

48. Birkenfeld S, Zvidi I, Hazazi R, Niv Y. The prevalence of ulcerative colitis in Israel: a twenty-year survey. J Clin Gastroenterol. 2009; 43:743-46. [PubMed: 19369888]

49. Kekilli M, Dagli U, Kalkan IH, et al. Low incidence of colorectal dysplasia and cancer among patients with ulcerative colitis: a Turkish referral centre study. Scand J Gastroenterol. 2010; 45:434-39. [PubMed: 20085438]

50. Kusakcioglu O, Kusakcioglu A, Oz F. Idiopathic ulcerative colitis in Istanbul: clinical review of 204 cases. Dis Colon Rectum. 1979; 22:350-55. [PubMed: 467205]

51. Al-Shamali MA, Kalaoui M, Patty I, Hasan F, Khajah A, Al-Nakib B. Ulcerative colitis in Kuwait: a review of 90 cases. Digestion. 2003; 67:218-24. [PubMed: 12966229]

52. Senanayake SM, Fernandopulle AN, Niriella MA, et al. The long-term outcomes of a cohort of Sri Lankan patients with ulcerative colitis: a retrospective study at two national referral centers and review of literature. Clin Exp Gastroenterol. 2013; 6:195-200. [PubMed: 24068873]

53. Ghazzawi I, Al-Mrayat Z. Review of chronic ulcerative colitis cases at King Hussein Medical Centre, Jordan. East Mediterr Health J. 2007; 13:294-300. [PubMed: 17684851]

54. Aghazadeh R, Zali MR, Bahari A, Amin K, Ghahghaie F, Firouzi F. Inflammatory bowel disease in Iran: a review of 457 cases. J Gastroenterol Hepatol. 2005; 20:1691-95. [PubMed: 16246187]

55. Radhakrishnan S, Zubaidi G, Daniel M, Sachdev GK, Mohan AN. Ulcerative colitis in Oman. A prospective study of the incidence and disease pattern from 1987 to 1994. Digestion. 1997; 58:266-70. [PubMed: 9243122]

56. Mukewar S, Mukewar S, Limaye K, Lopez R, Wu X, Shen B. Environmental factors impact the natural history of ulcerative colitis (UC): Indian-Americans with UC have a higher risk for colectomy than Asian Indian counterparts. Gastroenterology. 2012; 142:S-784.

57. Jess T, Rungoe C, Peyrin-Biroulet L. Risk of colorectal cancer in patients with ulcerative colitis: a meta-analysis of population-based cohort studies. Clin Gastroenterol Hepatol. 2012; 10:639-45. [PubMed: 22289873]

58. Lutgens MW, van Oijen MG, van der Heijden GJ, Vleggaar FP, Siersema PD, Oldenburg B. Declining risk of colorectal cancer in inflammatory bowel disease: an updated meta-analysis of population-based cohort studies. Inflamm Bowel Dis. 2013; 19:789-99. [PubMed: 23448792]

59. Castaño-Milla C, Chaparro M, Gisbert JP. Systematic review with meta-analysis: the declining risk of colorectal cancer in ulcerative colitis. Aliment Pharmacol Ther. 2014; 39:645-59. [PubMed: 24612141] 
60. Söderlund S, Brandt L, Lapidus A, et al. Decreasing time-trends of colorectal cancer in a large cohort of patients with inflammatory bowel disease. Gastroenterology. 2009; 136:1561-67. [PubMed: 19422077]

61. Jess T, Simonsen J, Jørgensen KT, Pedersen BV, Nielsen NM, Frisch M. Decreasing risk of colorectal cancer in patients with inflammatory bowel disease over 30 years. Gastroenterology. 2012; 143:375-81. e1. [PubMed: 22522090]

62. Lutgens MW, Oldenburg B, Siersema PD, et al. Colonoscopic surveillance improves survival after colorectal cancer diagnosis in inflammatory bowel disease. Br J Cancer. 2009; 101:1671-75. [PubMed: 19826420] 


\section{Research in context}

\section{Evidence before this study}

The risk of colorectal cancer in long-standing ulcerative colitis is well known, but the estimates of risk have varied widely. Several efforts have been made in the past to assess the global burden of colorectal cancer associated with ulcerative colitis. A landmark meta-analysis by Eaden and colleagues on the risk of colorectal cancer in ulcerative colitis published in 2001 serves as a best estimate. The overall prevalence of colorectal cancer in ulcerative colitis, based on 116 studies, was estimated to be $3.7 \%$ (95\% CI 3.2$4 \cdot 2$ ). The cumulative probabilities were $2 \%$ by 10 years, $8 \%$ by 20 years, and $18 \%$ by 30 years. More recent estimates have shown a decreasing trend in the risk of colorectal cancer in ulcerative colitis. A recent meta-analysis by Castaño-Milla and colleagues revealed a lower incidence of colorectal cancer at 1.58 per 1000 patient-years. Another meta-analysis by Jess and colleagues also suggested that the risk of colorectal cancer in ulcerative colitis has been declining, with an overall occurrence of $1.6 \%$ over 14 years. However, there has been a paucity of data looking at the regional variations and the risk of colorectal cancer exclusively in Asian patients with ulcerative colitis. We searched PubMed from inception to July 1, 2016, without language restrictions, using the terms "ulcerative colitis" and "colorectal cancer" and the article type was filtered as metaanalysis. We retrieved 31 studies. We found no meta-analysis that examined the risk of colorectal cancer in ulcerative colitis in Asian populations exclusively, to see whether the risk was any different from those in European and North American populations. Added value of this study. Our study aimed to estimate the risk of colorectal cancer in ulcerative colitis from studies published from Asian countries. A meta-analysis of the several studies reporting the risk of colorectal cancer in ulcerative colitis from this region is lacking. As there exist ethnic differences in susceptibility to ulcerative colitis as well as colorectal cancer, it is important for accurate estimates of colorectal cancer risk in populations where inflammatory bowel disease is emerging, to accurately inform patient care and surveillance practices. Implications of all the available evidence In this systematic review and meta-analysis, we found a prevalence of colorectal cancer in patients with ulcerative colitis of $0.85 \%$ in Asia, with no further geographical variation within this region. This overall prevalence is much lower than the prevalence of $3.7 \%$ reported by Eaden and colleagues in their meta-analysis of 116 studies. The cumulative risk at 30 years in our analysis was $13.91 \%$, compared with $18 \%$ in Eaden and colleagues' study. However, more recent studies that have examined secular decline in colorectal cancer rates in ulcerative colitis have arrived at a similar prevalence in western populations to our results. For example, Jess and colleagues estimated an overall prevalence of colorectal cancer in patients with ulcerative colitis of $1.6 \%$ in their metaanalyses of population-based studies, slightly higher than our estimate. In an analysis of cumulative incidence, Lutgens and colleagues estimated a risk of $1 \%, 2 \%$, and $5 \%$ after 10 years, 20 years, and more than 20 years of disease duration, similar to our estimates. In light of this previous evidence, there are a few implications from our study. First, though the risk of sporadic colorectal cancer is much lower in Asian countries than in North America and Europe, we found the prevalence estimates of colorectal cancer in patients with ulcerative colitis to be similar or only slightly lower than recent estimates 
from other meta-analyses. Consequently, regional recommendations need to emphasise the importance of such surveillance programmes in patients with long-standing ulcerative colitis. As use, acceptance, and cost of colonoscopies might prove to be important barriers, there is a need for further examination of non-invasive screening tools for colorectal cancer in patients from resource-poor settings. Also, there might be a need to treat to mucosal healing to reduce the risk of colorectal cancer in those with longstanding ulcerative colitis. 

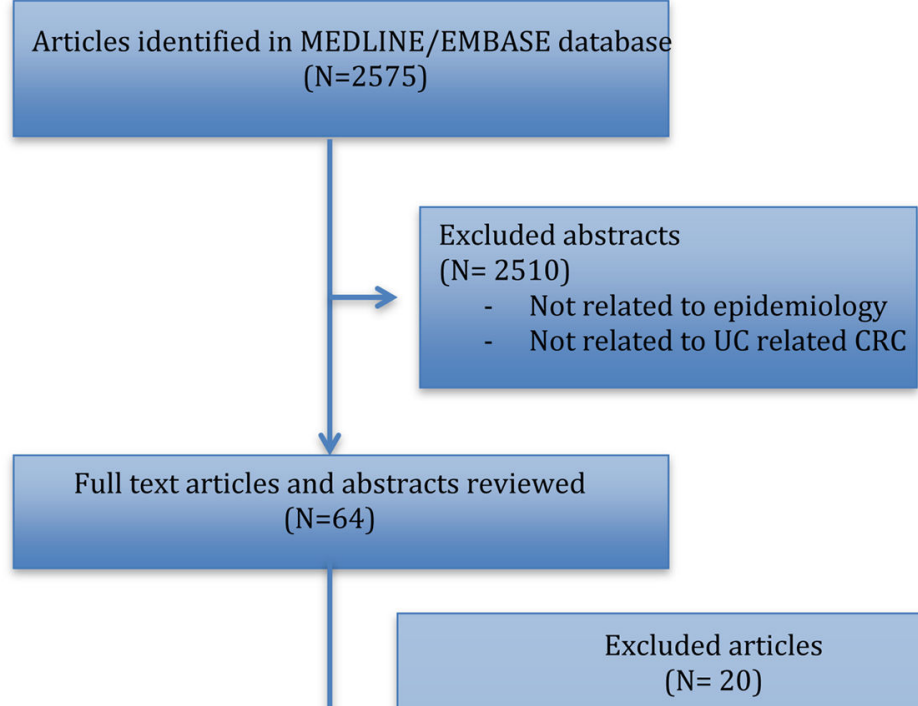

2 -Descriptive studies with no information on prevalence/incidence

1 - CRC in pouch after colectomy

6 - Data presented as IBD. No mention of UC CRC

1-included only those with ulcerative proctitis 1- Data on UC CRC only in patients who died 3- Surgical series which included only patients with UC CRC/dysplasia

1-No abstract or full text available

1- Epidemiology of IBD- No mention of UC CRC

4- Surgical series

Studies included in the analysis $(\mathrm{N}=44)$

Figure 1.

Flow chart depicting literature search 


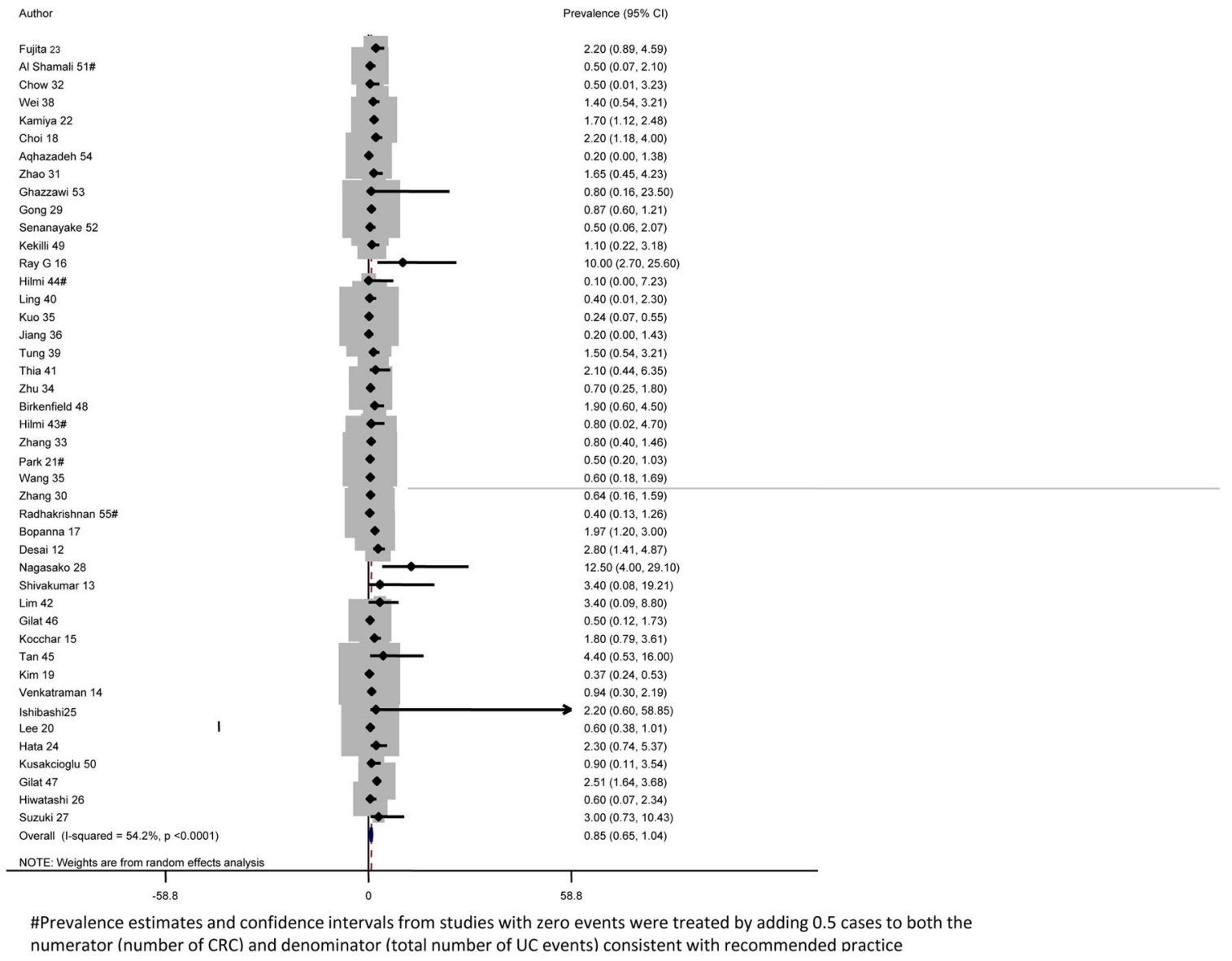

Figure 2.

\#Prevalence estimates and confidence intervals from studies with zero events were treated by adding 0.5 cases to both the numerator (number of CRC) and denominator (total number of UC events) consistent with recommended practice 
Figure 3a

Author

Cumulative risk $(95 \% \mathrm{Cl}))$

\section{Hata 24}

Lee 18

Gong 29

Wei 38

Kim 19

Gilat 47

Bopanna 17

Venkatraman 14

Senanayake 52

Desai 12

Overall $(\mathrm{I}$-squared $=88.6 \%, p<0.0001)$

NOTE: Weights are from random effects analysis
$0.50(0.01,2.56)$

$0.30(0.12,0.56)$

$1.15(0.83,15.35)$

$0.00(0.00,0.01)$

$0.70(0.51,0.91)$

$0.20(0.02,0.69)$

$1.50(0.82,2.44)$

$0.00(0.00,0.01)$

$0.47(0.06,2.07)$

$2.50(1.27,4.57)$

$0.02(0.0,0.04)$ 


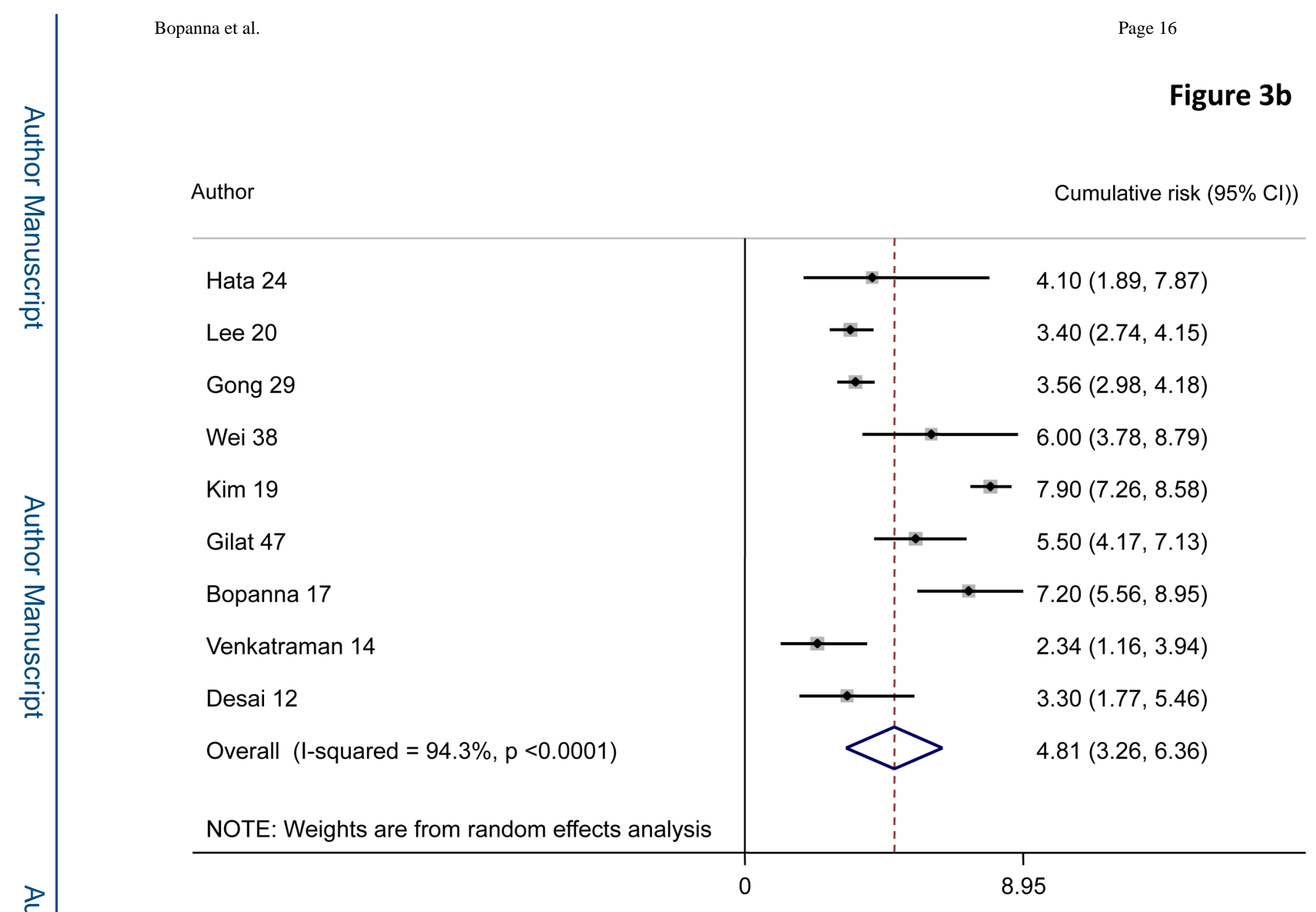

Figure $3 c$

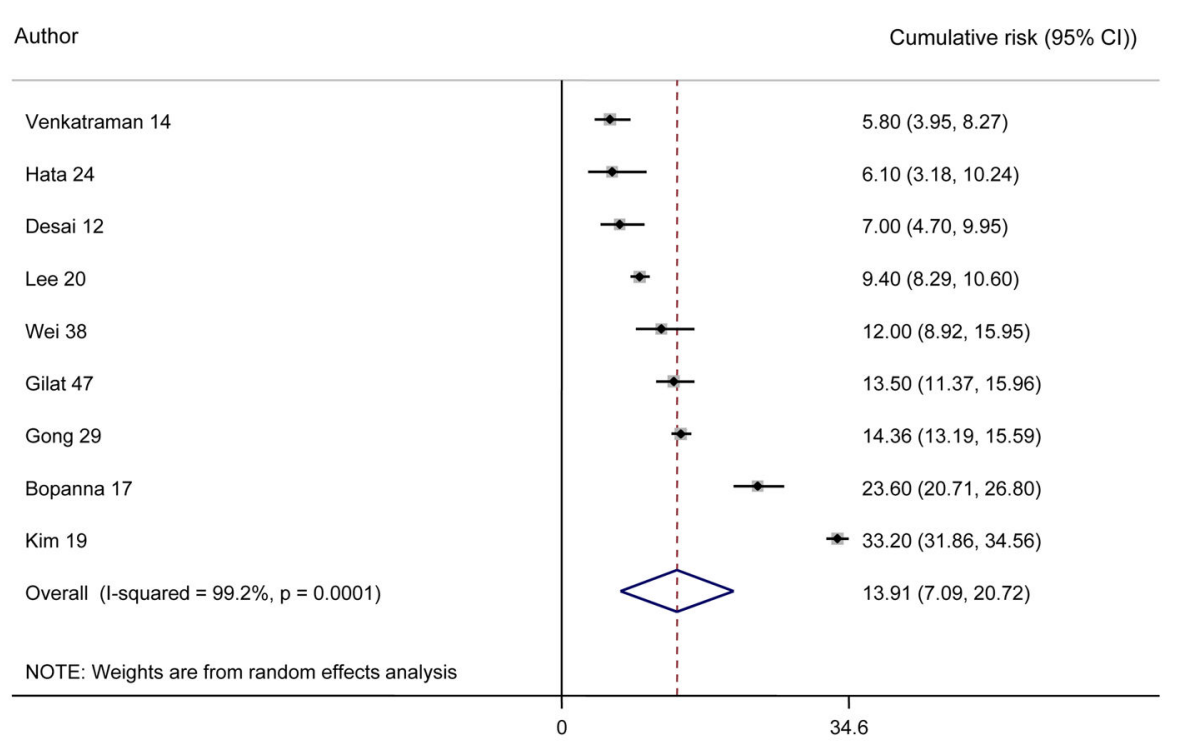

Lancet Gastroenterol Hepatol. Author manuscript; available in PMC 2017 December 04. 
Figure 3. 


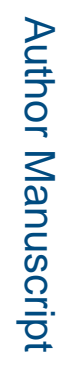

\begin{tabular}{|c|c|c|c|c|c|c|c|c|c|c|c|c|c|c|c|c|c|c|c|c|c|c|c|c|}
\hline $\begin{array}{l}0 \\
0 \\
\infty \\
i \\
\sim\end{array}$ & \begin{tabular}{l}
80 \\
\multirow{3}{+}{} \\
$m$
\end{tabular} & $\begin{array}{l}0 \\
\vdots \\
0\end{array}$ & 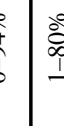 & 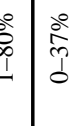 & $\begin{array}{l}8 \\
0 \\
0 \\
1\end{array}$ & $\begin{array}{l}0 \\
0 \\
0 \\
0 \\
0\end{array}$ & : & 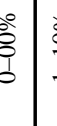 & $\frac{8}{1}$ & 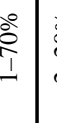 & ते & 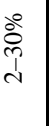 & 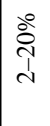 & $\begin{array}{l}\text { : } \\
0 \\
0\end{array}$ & $\begin{array}{l}\text { of } \\
0 \\
0 \\
0\end{array}$ & $\begin{array}{l}\stackrel{0}{0} \\
\infty \\
0 \\
0\end{array}$ & $\begin{array}{l}\stackrel{8}{0} \\
\dot{b} \\
1\end{array}$ & $\begin{array}{l}0 \\
0 \\
0 \\
0\end{array}$ & 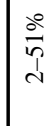 & 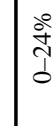 & & 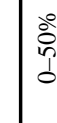 & & $\begin{array}{l}80 \\
\text { İ } \\
\text { İ }\end{array}$ \\
\hline
\end{tabular}

ב


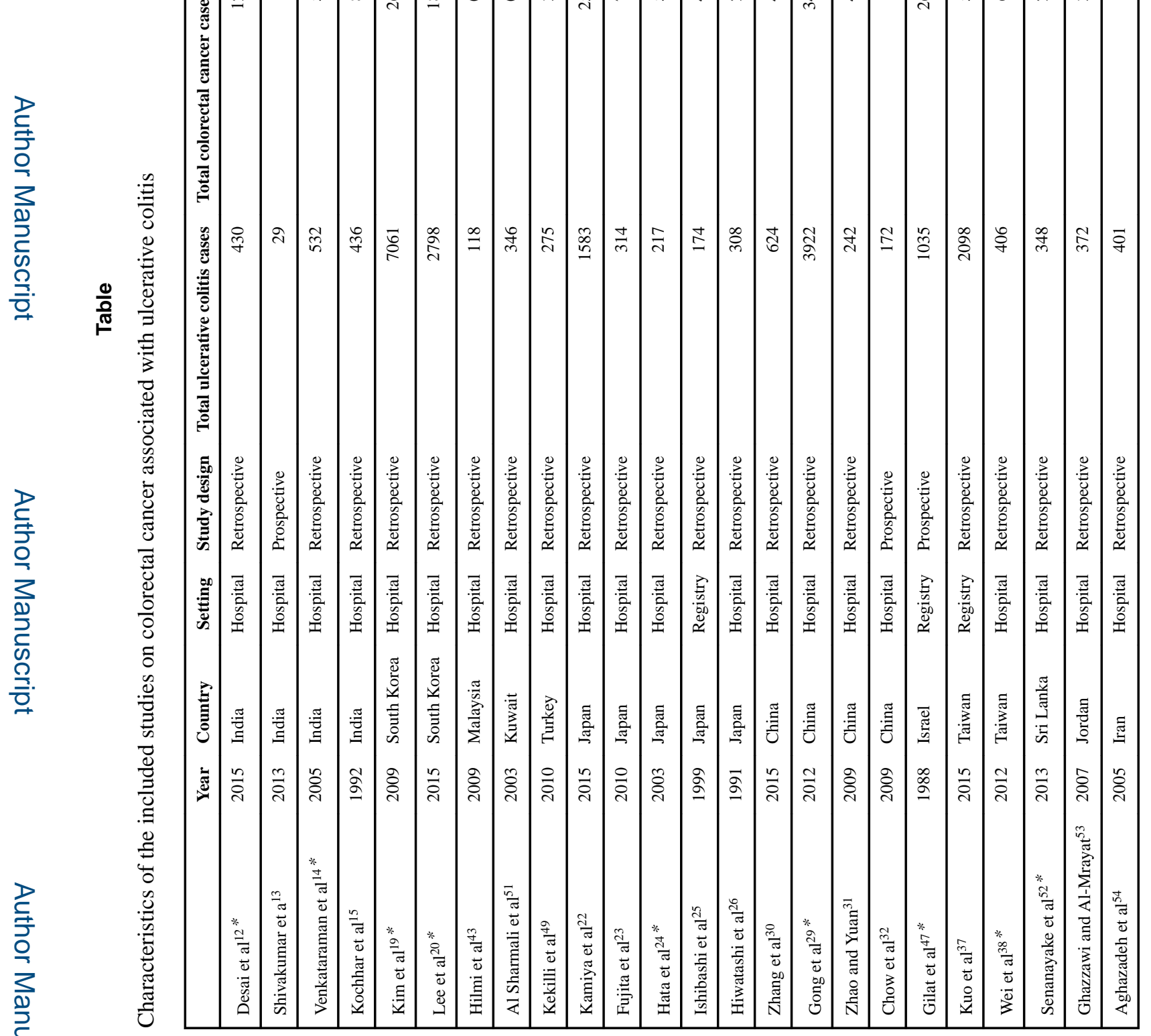

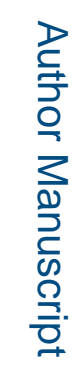

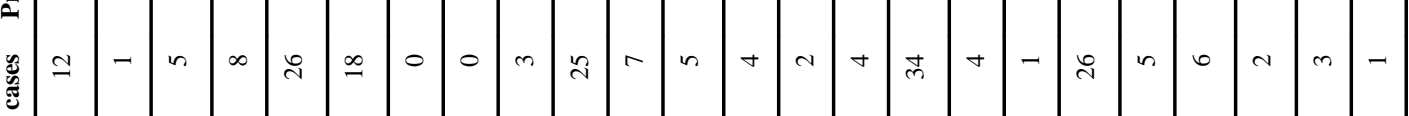
Lancet Gastroenterol Hepatol. Author manuscript; available in PMC 2017 December 04. 


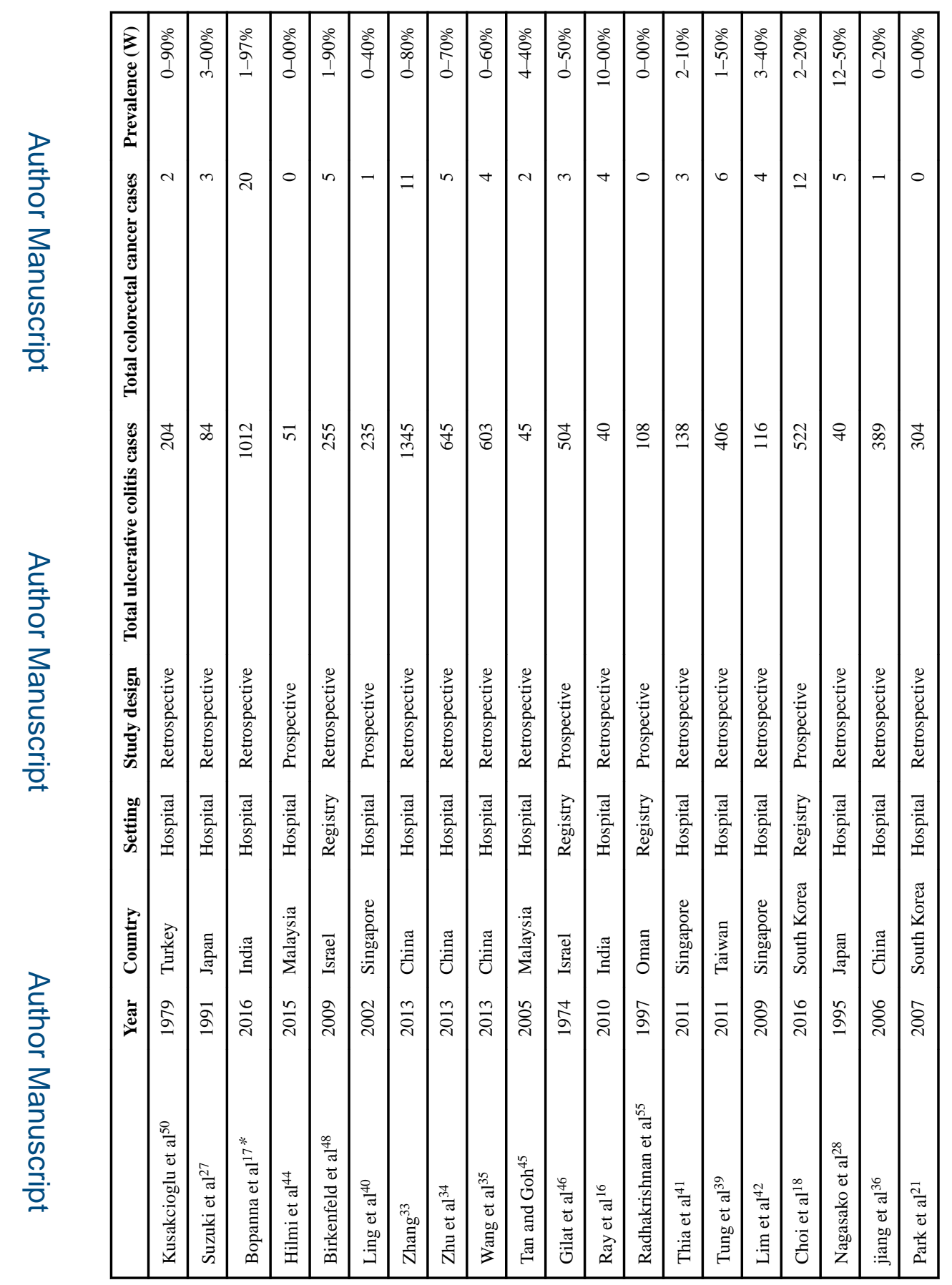

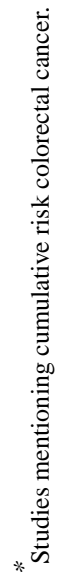

로을 